\title{
DIE EINHEIT DER NATURKRÄFTE IN DER THERMODYNAMIK
}

EINE MATHEMATISCH-PHYSIKALISCH-SPEKULATIVE ABLEITUNG DER CHEMISCHEN, ELEKTRISCHEN UND REIN MECHANISCHEN SONDERKRÄFTE, EINSCHLIESSLICH DER SCHWERKRAFT AUS DER KINETISCHEN ENERGIE BEWEGTER UNELASTISCHER KÖRPER- UND ÄTHER-ATOME

$$
\text { voN }
$$

\section{RICHARD WEGNER}

MIT EINER PORTRAITVIGNETTE UND ZAHLREICHEN FIGUREN

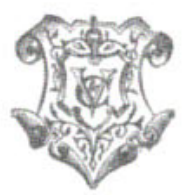

LEIPZIG

VERLAG VON VEIT \& COMP. 


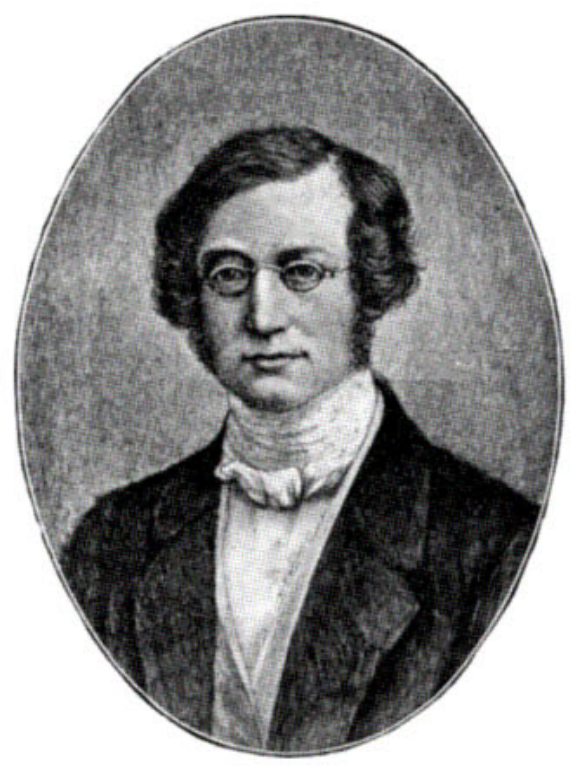

Robert Mayer

nach einem Daguerreotyp aus dem Jahre 1848

Druck von Metzger \& Wittig in Leipzig. 